\title{
NEW METHODS OF NATURAL GAS ADJUSTING FOR TECHNOLOGICAL PURPOSES BASED ON MODERN FILTRATION MATERIALS
}

\author{
NOWE METODY PRZYGOTOWANIA GAZU ZLOŻOWEGO \\ DO CELÓW TECHNOLOGICZNYCH Z UŻYCIEM NOWOCZESNYCH \\ MATERIAŁÓW FILTRACYJNYCH
}

\begin{abstract}
Reservoir gas treatment technologies currently in use require significant investments in equipment and materials. Considering the foregoing, new technologies are sought for treatment and separation of components of extracted gas. They will guarantee compliance with gas quality requirements arising from applicable standards while at the same time lowering the costs of investment, service and environmental protection. Therefore, the purpose of this work was to develop an efficient mobile technology for natural gas treatment, on the basis of advanced filtering and coalescing materials and membranes, which eliminate the existing, economically non-viable processes and reduce the costs related to development of new reservoirs. The purpose of designed materials was removal of solid particles, water, higher hydrocarbons and nitrogen from natural gas. Presented integrated filtration and membrane system, characterized by a highly compact design enabling installation in container stations and transporting the system between specific points of production.
\end{abstract}

Keywords: natural gas treatment, membranes, fibrous filters, coalescers

\section{Introduction}

Over 2.5 trillion cubic meters of natural gas is produced worldwide every year. The United States are the leader in this production, followed closely by Russia. These two countries account for over $1 / 3$ of overall natural gas mining globally. Gas mining in Poland in 2016 ranges around 3.9 billion cubic meters, which constitutes $0.11 \%$ of global production output and $1.56 \%$ of the output of the European Union [1]. It should be emphasized, however, that this rank may change as a consequence of production of shale gas.

\footnotetext{
${ }^{1}$ Faculty of Chemical and Process Engineering, Warsaw University of Technology, ul. L. Waryńskiego 1, 00-645 Warszawa, Poland, phone +48 2223462 47, fax +48 22825 1440, email: anna.jackiewicz@pw.edu.pl

${ }^{2}$ Faculty of Materials Science and Engineering, Warsaw University of Technology, ul. Wołoska 141, 02-507 Warszawa, Poland

*Corresponding author: anna.jackiewicz@pw.edu.pl
} 
Composition of natural gas varies depending on the point of intake and does not vary greatly in terms of type of contaminants [2]. It is mainly composed of methane, $\mathrm{CH}_{4}$ (70-90\%), as well as higher hydrocarbons (ethane, propane, butane and higher), in proportions that may reach even several percent. In addition, this gas contains significant quantities of water, carbon dioxide, hydrogen sulfide, nitrogen, and solid particles (sand, debris, rust). The Polish Standard PN-C-04753:2011 [3] sets out the maximum values of contaminant contents in gas injected to gas systems. The natural gases transmitted via the gas network should not consist excessive contents of dust, hydrogen sulfide, steam which can cause damage of gas pipeline materials (erosion, abrasion and corrosion). Their occurrence leading to deterioration of flow capacity in gas pipelines as a result of steam condensation, hydrocarbon condensation, hydrate formation and dust deposition. Moreover, there should be no gas explosion hazard, for which reason higher hydrocarbons need to be removed. There are also other reasons necessitating removal of methane contaminating components from natural gas, namely to increase the heating value of gas through nitrogen separation, and to reduce the volume of transmitted gas and therefore the costs of transmission.

Thus, natural gas produced from wells requires treatment, which mainly includes removal of solid particles, moisture, heavy hydrocarbons, nitrogen. Contemporary technologies require major investments in equipment, materials and energy. The most commonly applied solution in industry practice is mechanical separation of liquid and solid particles from gas flows with various types of equipment, such as gravity separators or centrifugal separators. The review of the conventional and unconventional natural gas treatment technologies are presented in works by Alcheikhhamdon and Hoorfar [4] and Rufford et al. [5]. The need to eliminate the problems i.e. large system size, causing high investment costs, gas drying technology with the use of glycol, currently faced by the production industry, leads to the necessity of developing new natural gas treatment systems.

Therefore, the purpose of this work was to develop innovative material solutions (coalescing filters and membranes) to build natural gas treatment systems that are smaller, more energy efficient and environmentally friendly than the existing options, which will also be possibly mobile. Such stations could be used for many years on various natural gas sources.

\section{Membranes for drying natural gas, removing heavy hydrocarbon and nitrogen}

Industrial acceptance for membranes in gas separation processes is getting higher. Membranes are considering in such processes as biogas upgrading, natural gas sweetening, air components separation, air and natural gas dehydrating [6,7]. They are also used in the treatment of water containing various micropollutants for drinking and industrial purposes [8].

Membrane techniques are currently an innovation in designing natural gas treatment apparatus [9]. These techniques account for only less than 5\% of the market of such apparatus, which is worth about 5 billion US dollars yearly, and the vast majority of solutions are focused on eliminating carbon dioxide only [10,11]. The remaining areas of natural gas treatment, i.e. removal of water, higher hydrocarbons and inert gases with the use of membrane techniques are not fully investigated or developed. In this work the semi-permeable membranes were applied for dehydration of natural gas. They were 
designed and produced especially for this purpose. This solution enables elimination of glycol absorbers from the process line and a major reduction of sizes of a dehydration system. The production industry pins its high hopes on nitrogen removal with gas separation membranes.

In the subject of membrane techniques, the Authors' own membranes have been prepared. Polypropylene capillary membranes have been used as a support layer for a dense separation layer. Dense layers have been obtained with the dip coating method [12, 13]. In membranes for gas dewatering, the dense separation layer has been made from a solution of copolymer Pebax 1074 and the silica nanoparticles of different sizes. For membrane preparation, various concentrations of the polymer in the solvent and various concentrations of nanoparticles in the polymer have been used. Depending on the composition of the separation layer, such layers had varying thickness in the range of 9 to about 100 microns. Membrane thickness depends on such parameters as polymer solution viscosity and surface tension as well as on withdrawal velocity. We have used solutions whose viscosity was in the range $30-300 \mathrm{mPa} \cdot \mathrm{s}$ and their surface tension: $20-22 \mathrm{mN} / \mathrm{m}$. The withdrawal velocity has been regulated in the range $0-1000 \mathrm{~mm} / \mathrm{min}$. The structure of the manufactured membranes has been evaluated using an electron microscope. Figure 1 shows examples of such membranes. It should be noted that the repeatability and quality of our own membranes is very high. Their coatings are very uniform along the length of the membranes.

The membrane modules used in tests have been built with 10 capillaries with the length of $1 \mathrm{~m}$. Studies carried out for the natural gas dewatering were widely presented in the previous paper [14]. In general, 80\% efficiency of water removal has been obtained. It has been done for mixture of methane and water as well as for natural gas from a real well.

a)

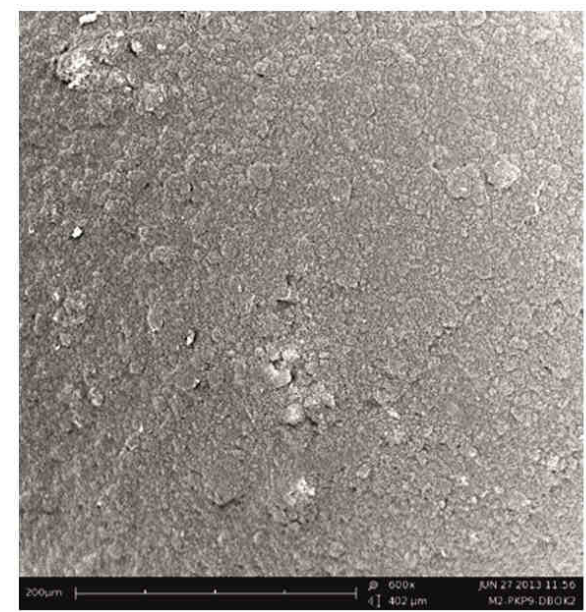

b)

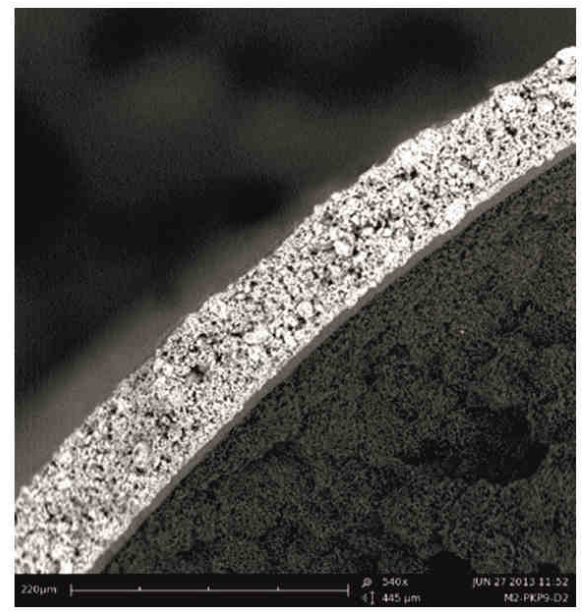

Fig. 1. SEM pictures of membranes: a) lateral surface, b) cross-section

In order to remove heavy hydrocarbons and nitrogen, a new type of membranes has been proposed. They have been manufactured from the suspension of zeolite A4 in the 
solution of copolymer Pebax 2533 in 2-butanol. A series of various modifications that differ in the concentration of polymer in the solution and the concentration of zeolite in the suspension has been examined.

In the first stage of the studies, the thickness of the selective layer of the capillary was assessed. The purpose of the modification was to obtain the lowest thickness possible, while providing continuity of the layer on the whole surface. The main influence on the thickness and continuity of the layer was exerted by a selective concentration of the polymer solution. With the increasing polymer solution's concentration, the selective layer's thickness also increased. The obtained layers had an average thickness from 4.63 microns to 32.24 microns. Additionally, it has been noted that for a given amount of polymer in the solution, the introduction of larger amounts of the zeolite results in an increase in layer thickness.

Separation properties of the prepared modules have been tested for pure gases: carbon dioxide, nitrogen and methane. The permeate flow has been measured for different pressures. Exemplary results for the selected membrane are shown in Table 1. On this basis, permeability coefficients and ideal separation factors have been calculated.

Analyzing the obtained research results (Table 1), it can be stated that, in general, the introduction of nanoparticles into the polymer structure improves the separation properties of the membrane. However, an increase in selectivity results in a decrease in permeability.

Test results for the selected membrane module

Table 1

\begin{tabular}{|c|c|c|c|c|c|c|c|c|c|}
\hline \multirow{2}{*}{$\begin{array}{c}\text { Feed } \\
\text { pressure } \\
\mathbf{1 0}^{-5}[\mathrm{~Pa}]\end{array}$} & \multicolumn{3}{|c|}{ Permeate flow $\left[\mathrm{cm}^{3} / \mathrm{min}\right]$} & \multicolumn{3}{|c|}{ Permeability [barrer] } & \multicolumn{3}{|c|}{ Ideal selectivity factor [-] } \\
\hline & $\mathrm{CH}_{4}$ & $\mathbf{N}_{2}$ & $\mathrm{CO}_{2}$ & $\mathrm{CH}_{4}$ & $\mathbf{N}_{2}$ & $\mathrm{CO}_{2}$ & $\mathrm{CH}_{4} / \mathrm{N}_{2}$ & $\mathrm{CO}_{2} / \mathrm{CH}_{4}$ & $\mathrm{CO}_{2} / \mathrm{N}_{2}$ \\
\hline 1 & - & - & 1.9 & - & - & 16.4 & - & - & - \\
\hline 1.5 & 1.8 & 1.1 & 7.5 & 10.6 & 6.5 & 44.0 & 1.7 & 4.1 & 6.8 \\
\hline 2 & 3.1 & 1.9 & 15.5 & 13.7 & 8.4 & 68.0 & 1.6 & 5.0 & 8.1 \\
\hline 2.5 & 7.6 & 2.8 & 22.6 & 26.6 & 9.8 & 79.2 & 2.7 & 3.0 & 8.1 \\
\hline 3 & 10.9 & 4.9 & - & 31.8 & 14.3 & - & 2.2 & - & - \\
\hline
\end{tabular}

Additional tests have been conducted for a mixture of polymers. Polymers Pebax 2533 and Pebax 1074 have been mixed with polymer PEO, i.e., poly(ethylene oxide). The results obtained for these membranes are presented in Table 2.

Table 2

Test results for the membrane modules Pebax 1074 and 2533 with PEO

\begin{tabular}{|c|c|c|c|c|c|c|c|c|c|c|}
\hline \multirow{2}{*}{\multicolumn{2}{|c|}{$\begin{array}{c}\text { Membrane } \\
\text { composition }\left[\%_{\mathrm{w} / \mathrm{w}}\right]\end{array}$}} & \multirow{3}{*}{$\begin{array}{l}\text { Gas } \\
\mathrm{CH}_{4}\end{array}$} & \multirow{6}{*}{ 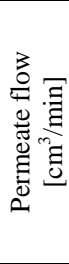 } & \multicolumn{6}{|c|}{ Feed pressure $10^{-5}[\mathrm{~Pa}]$} & \multirow{2}{*}{$\begin{array}{c}\text { Ideal } \\
\text { selectivity } \\
\text { factor } \\
\alpha_{\mathrm{CO} 2 / \mathrm{CH} 4}[-]\end{array}$} \\
\hline & & & & 1 & 1.5 & 2 & 2.5 & 3 & 4 & \\
\hline \multirow{2}{*}{$\begin{array}{c}\text { Pebax } 1074 \\
8 \%\end{array}$} & PEO & & & - & - & - & - & - & 1.84 & \multirow{2}{*}{18.98} \\
\hline & $2 \%$ & $\mathrm{CO}_{2}$ & & 35.02 & 34.66 & 34.07 & 35.24 & 35.67 & - & \\
\hline \multirow{2}{*}{$\begin{array}{c}\text { Pebax } 2533 \\
8 \%\end{array}$} & PEO & $\mathrm{CH}_{4}$ & & 27.99 & 26.77 & 27.24 & 28.80 & 28.55 & - & \multirow{2}{*}{4.96} \\
\hline & $2 \%$ & $\mathrm{CO}_{2}$ & & 142.92 & 137.15 & 136.19 & 138.43 & 136.94 & - & \\
\hline
\end{tabular}

Comparing data collected in Tables 1 and 2, it can be stated that the presence of PEO in the polymer solution improves the membrane properties. 
In Table 3 comparison of experimental work for laboratory $\mathrm{N}_{2} / \mathrm{CH}_{4}$ mixture and for natural gas was presented, where $x_{N}$ is a molar fraction of component in feed, and $x_{P}$ is a molar fraction in permeate.

Gas composition in feed $\left(x_{N}\right)$ and permeate $\left(x_{P}\right)$

\begin{tabular}{|c|c|c|}
\hline \multirow{3}{*}{$\begin{array}{c}\text { Laboratory gas mixture } \\
\mathrm{CH}_{4} / \mathrm{N}_{2}\end{array}$} & $x_{\mathrm{NCH}_{4}}$ & 0.65 \\
\cline { 2 - 3 } & $x_{N \mathrm{~N}}$ & 0.35 \\
\cline { 2 - 3 } & $x_{P_{\mathrm{CH}}}$ & 0.73 \\
\cline { 2 - 3 } & $x_{P \mathrm{~N}_{2}}$ & 0.27 \\
\hline \multirow{4}{*}{ Natural gas } & $x_{\mathrm{NCH}_{4}}$ & 0.82 \\
\cline { 2 - 3 } & $x_{\mathrm{NN}_{2}}$ & 0.13 \\
\cline { 2 - 3 } & $x_{\mathrm{PCH}_{4}}$ & 0.84 \\
\cline { 2 - 3 } & $x_{P \mathrm{~N}_{2}}$ & 0.12 \\
\hline
\end{tabular}

It can be observed that methane enrichment in permeate was higher for laboratory gas mixture than for natural gas. Natural gas contains not only nitrogen and methane, but also a lot of other components [15, 16]. Mutual competition for permeation through the membrane of all the components in natural gas can be the reason of such differences [17, 18]. Moreover, in natural gas contains water vapor. In this case water vapor permeates through the membrane and it can change the permeability of the membrane for the other components of natural gas. It should be mentioned that water vapor permeability is several thousand times higher than methane or nitrogen permeability [19]. So water vapor can limit the permeation for other components of natural gas.

\section{Fibrous filters for the removal of solid particles and droplets from gas}

As regards fibrous filters, they are already used in treatment of natural gas [20, 21]. However, the filters available on the market are all-purpose materials with all their advantages and disadvantages. The materials developed during this work have an advantage over these commercial ones because they are designed and manufactured for a specific purpose. Fibrous filtration cartridges which are currently manufactured are designed for removal of solid particles only or liquid droplets only (coalescing filter packs). Most of the published research results, both concerning experimental and theoretical studies, relate to removal of solid particles or of droplets only. However, in the case of natural gas, it is necessary to handle both solid particles and droplets of water appearing simultaneously, which need to be removed in a single separating structure. It seems obvious that for simultaneous deposition of droplets and solid particles in a filter, mutual interactions of these particles should be expected, namely the presence of liquid (droplets) affects solid deposit structures, while the presence of solid particles impacts the wettability of fibers by droplets. The research conducted within this work allow us to describe these relationships fully, thus opening the path to designing filters operating in an optimized manner in dynamic conditions. In order to describe the changes in efficiency as a result of loading with solid and liquid particles the approaches presented in works by Thomas et al. [22], Frising et al. [23] and Kasper et al. [24] were used to build our own mixed aerosol filtration model. On the other hand, the change of filtration efficiency as an effect of pre-coated of 
fibers with oil has been also reported $[25,26]$. The same effect is expected to be observed when such a "pre-coating" is not an effect of deliberate action but the presence of oil droplets in treated gas.

Procedure of modeling of dynamics of consecutive filtration (first solid then liquid particles) is as follows. First part of the simulation (filtration of solid aerosols) shows the growth of filtration efficiency due to dendrite-like deposits formation. According to idea presented by Thomas et al. [22], these deposits may be considered as additive fibers with diameter equal to mean particle diameter. That leads to decrease of porosity and change of mean fiber diameter. This effect has been also observed elsewhere [27]. While filtration of liquid aerosol starts, some of particles being a part of deposits are covered with thin liquid film. That leads to appearance of capillary [28] and liquid bridging forces [29] and thus to reorganization (collapse) of deposits and, finally, to change the efficiency of filters. Procedure and results of simulation has been presented in details in work by Gac et al. [30].

Fibrous filters were manufactured by us from polypropylene using the melt-blown technique. We developed a modified technology based on the molten polymer which allows us to produce filters with assumed structure composed of fibers with various diameters from nanometer to micrometer in size $[31,32]$. It enables formation of a filter structure for a particular purpose, for a specific type of pollutants. Additionally, the rate of fiber production with this method is much higher than for other techniques, i.e. electrospinning. This is very important from the point of view of the application of this method to industrial scale production.

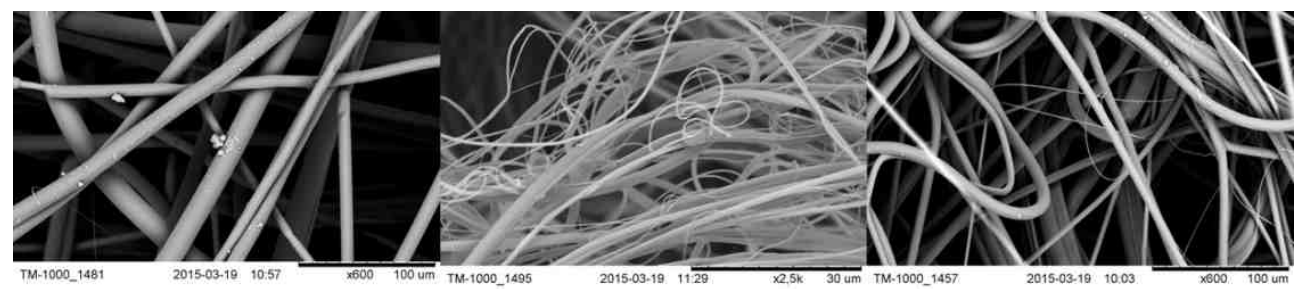

Fig. 2. Gradient fibrous filter composed of: microfibers (around 10 micrometer) - nanofibers microfibers (around 5 micrometers)

Structural parameters of the gradient filter layers

Table 4

\begin{tabular}{|c|c|c|}
\hline Filter layer & Mean fiber diameter $[\boldsymbol{\mu m}]$ & Packing density [-] \\
\hline Microfibers (f10) & 10.0 & 0.120 \\
\hline Nanofibers (nano) & $<1.0$ (typically 0.6-0.8) & 0.021 \\
\hline Microfibers (f5) & 5.0 & 0.059 \\
\hline
\end{tabular}

The quality of the designed media involves spatial inhomogeneity (gradient filters), followed by extended life and higher efficiency of the filter. Adding the peroxides to the polymer we were able to get a very thin fibers, which were incorporated to the final gradient material [32]. All filters considered in present work were composed of three layers (Fig. 2), characterized by different porosity and mean fiber diameter. The structural parameters of the individual layers forming the gradient structure are given in Table 4 . The fiber size distribution of each layer (mean fiber diameter and standard deviation) was determined on the basis of photos taken under scanning electron microscope (Hitachi 
TM-1000). Fifty images of each filter layer were analyzed and using tools of the Acrobat Professional program one hundred fiber diameters were measured.

All the newly formed structures were tested using highly advanced test benches from PALAS GmbH company (described in details in works by Gac et al. [30] and Jackiewicz et al. [33]) to examine both the filtration of solid particles and droplets of different diameter from nano to micrometer. The main parameters of fibrous filters, such as pressure drop and separation efficiency while loading filters with solid and liquid particles, were examined. The directions for the design of gradient structures came from studies of multilayers systems composed of three various materials arranged in different configurations.

Figure 3 shows the relationship between filtration efficiency as a function of droplet diameter, where efficiency is defined as the number of droplets deposited on the fibers to the number of droplets in the stream before the filter (in the feed stream). In the case of droplets removal from gas the worst long-term performance had filter, wherein the nano-layer was located at the end, which is caused by droplets easier re-entrainment from this layer (see Fig. 3b) while the initial efficiency of all the investigated filters is nearly the same (Fig. 3a). The signature of re-entrainment is an apparent decrease of efficiency of removal of the biggest droplet what is observed for filters f10-f5-nano and f10-nano-f5. In fact, the droplets with diameter greater than $5 \mu \mathrm{m}$ and observed downstream are those which has been re-entrained from the fibers. The least susceptible to resuspension and therefore most efficient in droplets filtration have these filters, which last layer was composed of microfibers - as evidenced by the lack of large droplets in the air flow downstream of the filter. In fact, in our previous works we have proven both experimentally and numerically that the intensity of re-entrainment is decreasing function of mean fiber diameter so this phenomenon is nearly absent for filters ending with f10 layer and is clearly observed for filters ending with f5 or nano layer. For the last one, re-entrainment may appear also for droplets much less than $5 \mu \mathrm{m}$, leading to additional decrease of observed filtration efficiency.

a)

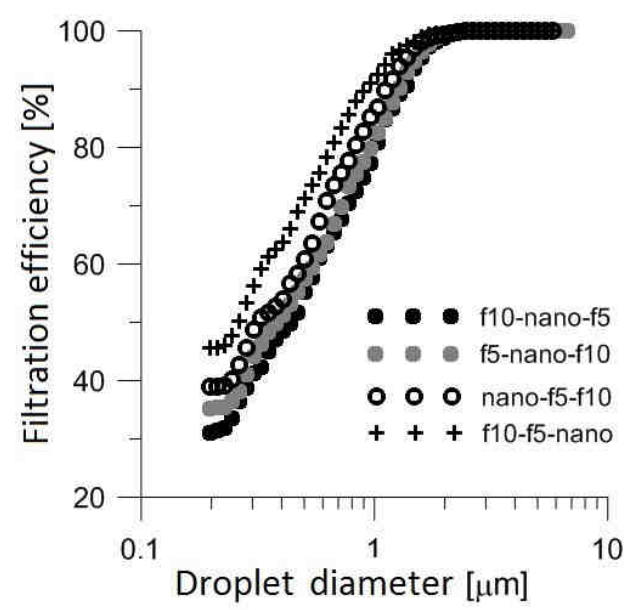

b)

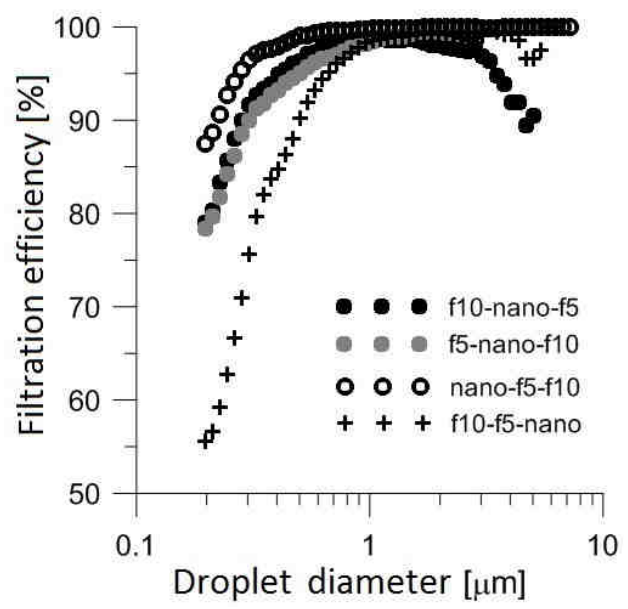

Fig. 3. Filtration efficiency of removal droplets from gas for four various gradient structures (composed of layers described in Table 4): a) at the beginning of the filtration process and b) upon reaching a pressure drop of $4.5 \mathrm{kPa}$ 
In the case of solid particles filtration filters having on the top layer of fibers with diameters in the nanoscale were characterized by rapidly increasing pressure drop (surface filtration) (Fig. 4). However, in materials that had a thicker fiber on the top pressure drop increased slower (depth filtration).

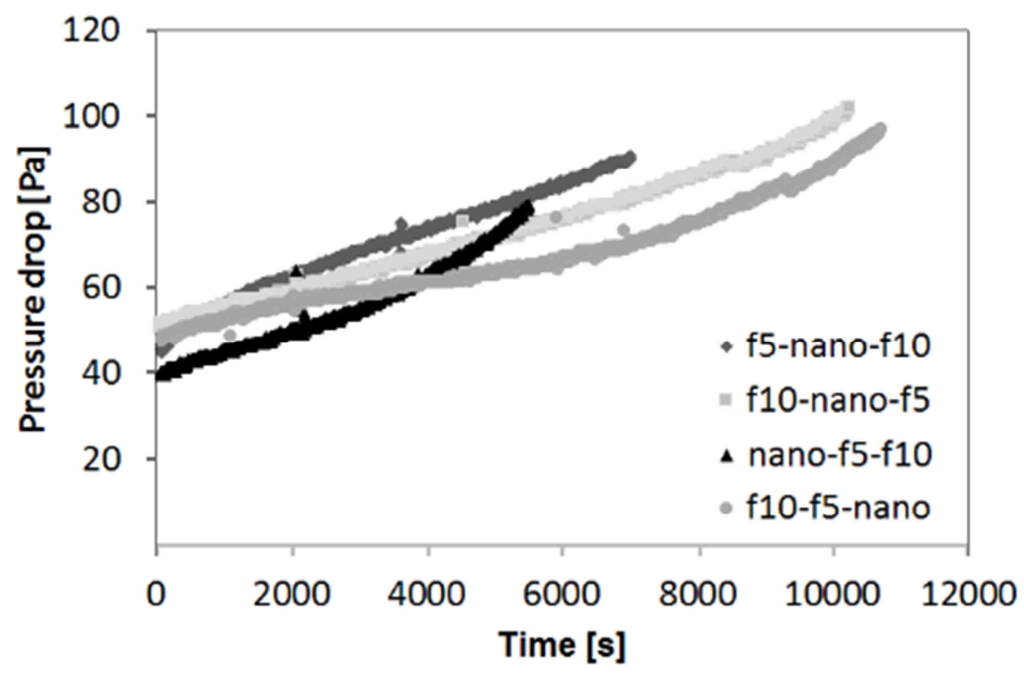

Fig. 4. Pressure drop for various gradient structure filters for solid particles filtration

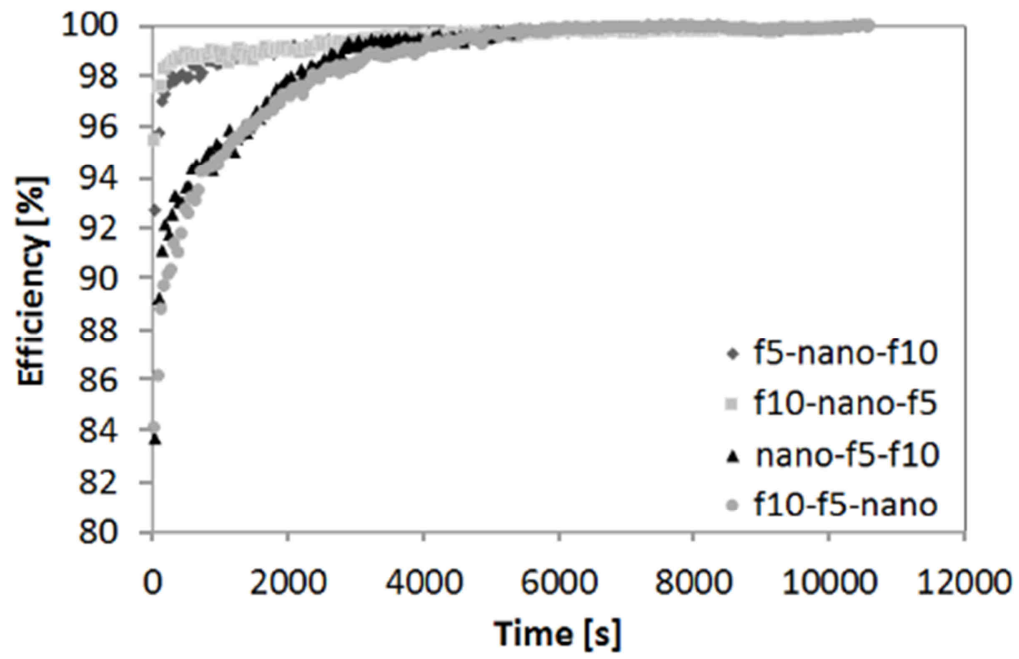

Fig. 5. Filtration efficiency for various gradient structure filters for solid particles filtration

Taking into account separation of both types of particles the optimal arrangement proved to be the following system: microfibers f10 (fibers diameter around 10 micrometer) 
- nanofibers - microfibers f5 (fibers diameter around 5 micrometers) (see Figs. 3-5), which was characterized by slowly increasing pressure drop, combined with high filtration efficiency, high dust capacity and lack of resuspension effect.

\section{Integrated system for natural gas treatment}

During this work a high-pressure installation for natural gas treatment was performed. It consists of three detachable modules: module of gas humidification (Fig. 6a), module for testing fibrous filters (Fig. 6b) and module for testing membranes (Fig. 6c). Each of these modules can be operated independently (separably) and as part of a series of processing. In these modules the materials developed within this work, i.e. membranes and coalescer filters, were applied.

a)

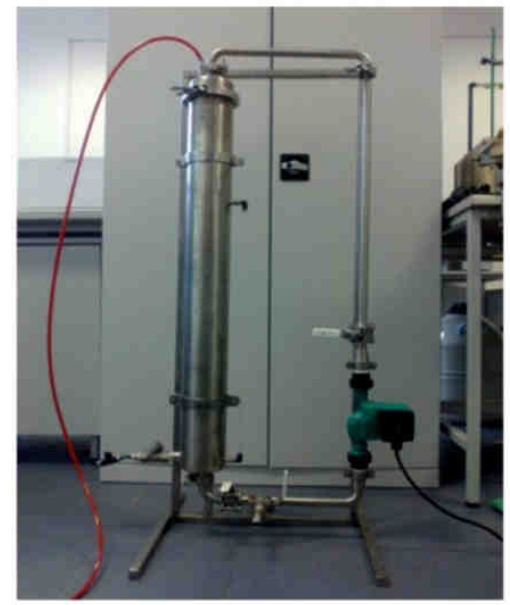

b)

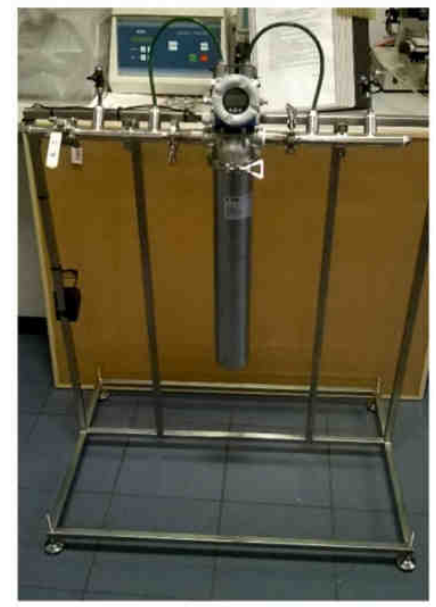

c)

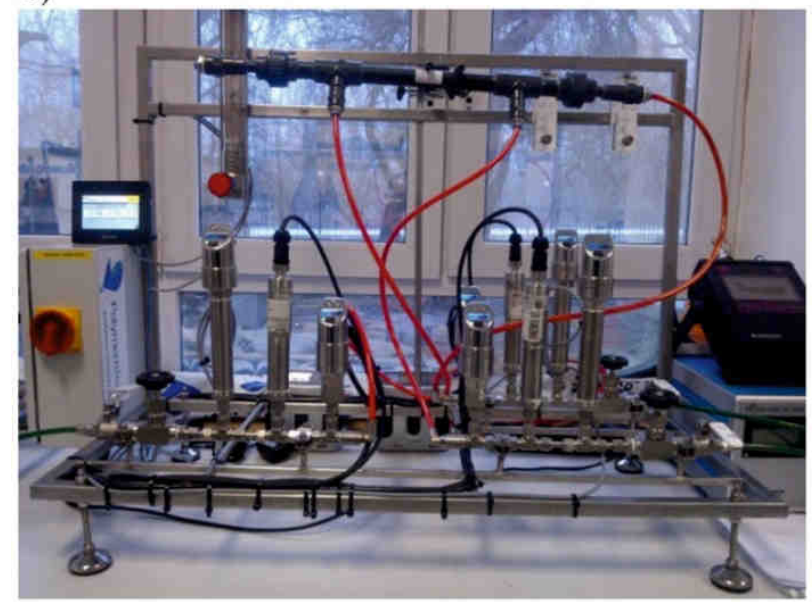

Fig. 6. Detachable modules: a) module of gas humidification, b) module for fibrous filter and c) module for membrane 
In the first stage the raw gas is humidified to a suitable water vapor content of the gas, then is pre-purified via fibrous filters (droplets and solids) and ultimately is directed to membranes for removing heavy hydrocarbon and nitrogen. Each module also allows direct connection of the gas chromatograph in order to perform measurements of the gas composition of individual streams during the experiment. The installation has been designed to allow you to work with explosive gases (e.g. methane). In order to ensure safety the system is protected by a stationary measure methane concentration and is also equipped with a portable methane detector, in order to periodically check the tightness of connections.

\section{Conclusions}

The scope of this work involved an analysis of natural gas treatment technology improvement options, development of new solutions and investigation of such new solutions. The new separation materials were designed and produced for this purpose. Results of research in the subject of membrane processes show that a new type of membranes for natural gas treatment has been developed. They can effectively remove the water from the stream of natural gas. Even $80 \%$ of water could be removed from the gas. In the subject of nitrogen removal, the obtained membranes are comparable to commercially available membranes. The obtained results for Pebax membranes are quite similar to the membranes obtained by Bondar et al. [34]. However, these membranes are characterized by quite good properties in $\mathrm{CO}_{2}$ and $\mathrm{CH}_{4}$ separation. As regards fibrous filters a gradient material, which effectively separates particles and droplets from the gas, working long, was successfully developed. Base on the melted polymer technology we can design a filter for a specific gas composition. During this work it was possible to simplify the technology and to make treatment system mobile with the use of fibrous filters and membranes, with modular and highly compact design.

\section{Acknowledgement}

This work has been supported by the National Centre for Research and Development Poland under the grant LIDER.

\section{References}

[1] BP Statistical Review of World Energy, June 2017. www.bp.com/content/dam/bp/en/corporate/pdf/ energy-economics/statistical-review-2017/bp-statistical-review-of-world-energy-2017-full-report.pdf.

[2] Faramawy S, Zaki T, Sakr AAE. Natural gas origin, composition, and processing: A review. J Nat Gas Sci Eng. 2016;34:34-54. DOI: 10.1016/j.jngse.2016.06.030.

[3] Polska Norma PN-C-04753: 2011. Gaz ziemny - Jakość gazu dostarczanego odbiorcom z sieci dystrybucyjnej (Polish Standard PN-C-04753: 2011: Natural gas - The quality of gas supplied to customers from the distribution network). http://sklep.pkn.pl/pn-c-04753-2011p.html.

[4] Alcheikhhamdon Y, Hoorfar M. Natural gas quality enhancement: A review of the conventional treatment processes, and the industrial challenges facing emerging technologies. J Nat Gas Sci Eng. 2016;34:689-701. DOI: 10.1016/j.jngse.2016.07.034.

[5] Rufford TE, Smart S, Watson GCY, Graham BF, Boxall J, Diniz da Costa JC, et al. The removal of $\mathrm{CO}_{2}$ and $\mathrm{N}_{2}$ from natural gas: A review of conventional and emerging process technologies, J Petrol Sci Eng. 2012;94-95:123-154. DOI: 10.1016/j.petrol.2012.06.016.

[6] Bernardo P, Drioli E, Golemme G. Membrane gas separation: a review/state of the art. Ind Eng Chem Res. 2009;48(10):4638-4663. DOI: 10.1021/ie8019032. 
[7] Szwast M. Membrany polimerowe do rozdzielania gazów (Polymeric membranes for gas separation). Przem Chem. 2012;91:1356-1361. www.sigma-not.pl/publikacja-69470-membrany-polimerowe-do-rozdzielaniagaz\%C3\%B3w-przemysl-chemiczny-2012-7.html.

[8] Bodzek M. Inorganic micropollutants removal by means of membrane processes. Ecol Chem Eng S. 2013;20(4):633-658. DOI: 10.2478/eces-2013-0044.

[9] Scholes CA, Stevens GW, Kentish SE. Membrane gas separation applications in natural gas processing. Fuel. 2012;96:15-28. DOI: 10.1016/j.fuel.2011.12.074.

[10] Baker RW, Lokhandwala K. Natural gas processing with membranes: an overview. Industrial Eng Chem Res. 2008;47(7):2109-2121. DOI: 10.1021/ie071083w.

[11] Bernardo P, Drioli E. Membrane gas separation progresses for process intensification strategy in the petrochemical industry. Petroleum Chem. 2010;50(4):271-282. DOI: 10.1134/S0965544110040043.

[12] Zhang CH, Yang FL, Wang WJ, Chen B. Preparation and characterization of hydrophilic modification of polypropylene non-woven fabric by dip-coating PVA (polyvinyl alcohol). Separat Purif Technol. 2008;61(3):276-286. DOI: 10.1016/j.seppur.2007.10.019.

[13] Zhu J, Fan Y, Xu N. Modified dip-coating method for preparation of pinhole-free ceramic membranes. J Membrane Sci. 2011;367(1):14-20. DOI: 10.1016/j.memsci.2010.10.024.

[14] Szwast M. Nowe membrany do osuszania gazu ziemnego (New membranes for dehydration of natural gas). Przem Chem. 2015;94(12):2213-2217. DOI: 10.15199/62.2015.12.25.

[15] Snowdon LR. Natural gas composition in a geological environment and the implications for the processes of generation and preservation. Organic Geochem. 2001;32(7):913-931. DOI: 10.1016/S0146-6380(01)00051-1.

[16] Freeman C, Moridis GJ, Michael GE, Blasingame TA. Measurement, modeling, and diagnostics of flowing gas composition changes in shale gas wells. In: SPE Latin America Caribbean Petroleum Eng Conf. Soc Petroleum Engineers. 2012. DOI: 10.2118/153391-MS.

[17] Koros WJ, Walker DRB. Gas separation membrane material selection criteria: weakly and strongly interacting feed component situations. Polymer J. 1991;23(5):481-490. DOI: 10.1295/polymj.23.481.

[18] Sridhar S, Smitha B, Aminabhavi TM. Separation of carbon dioxide from natural gas mixtures through polymeric membranes - a review. Separation Purif Rev. 2007;36(2):113-174. DOI: $10.1080 / 15422110601165967$.

[19] Metz SJ, Van de Ven WJC, Potreck J, Mulder MHV, Wessling M. Transport of water vapor and inert gas mixtures through highly selective and highly permeable polymer membranes. J Membrane Sci. 2005;251(1-2):29-41. DOI: 10.1016/j.memsci.2004.08.036.

[20] Baisong L, Zhongli J, Xue Y. Evaluation of gas-liquid separation performance of natural gas filters. Petrol Sci. 2009;6:438-444. DOI: 10.1007/s12182-009-0067-z.

[21] Zhen L, Zhongli J, Jinfeng Z, Lanjie L. Influence of processing parameters on gas-liquid filtration performance of fibrous filter cartridge. Procedia Eng. 2015;102:911-920. DOI: 10.1016/j.proeng.2015.01.212.

[22] Thomas D, Contal P, Renaudin V, Penicot P, Leclerc D, Vendel J. Modelling of pressure drop in HEPA filters during dynamic filtration. J Aerosol Sci. 1999;30:235-246. DOI: 10.1016/S0021-8502(98)00036-6.

[23] Frising T, Thomas D, Bemer D, Contal P. Clogging of fibrous filters by liquid aerosol particles: experimental and phenomenological modeling study. Chem Eng Sci. 2005;60:2751-2762. DOI: 10.1016/j.ces.2004.12.026.

[24] Kasper G, Schollmeier S, Meyer J, Hoferer J. The collection efficiency of a particle-loaded single fiber. J Aerosol Sci. 2009;40:993-1009. DOI: 10.1016/j.jaerosci.2009.09.005.

[25] Boskovic L, Agranovski IE, Braddock RD. Filtration of nanosized particles with different shape on oil coated fibres. J Aerosol Sci. 2007;38:1220-1229. DOI: 10.1016/j.jaerosci.2007.09.003.

[26] Müller TK, Meyer J, Thébault E, Kasper G. Impact of an oil coating on particle deposition and dust holding capacity of fibrous filters. Powder Technol. 2014;253:247-255. DOI: 10.1016/j.powtec.2013.11.036.

[27] Kasper G, Schollmeier S, Mayer J. Structure and density of deposits formed on filter fibers by inertial particle deposition and bounce. J Aerosol Sci. 2010;41:1167-1182. DOI: 10.1016/j.jaerosci.2010.08.006.

[28] Kralchevsky PA, Paunov VN, Nagayama K. Lateral capillary interaction between particles protruding from a spherical liquid layer. J Fluid Mech. 1995;99:105-132. DOI: 10.1017/S0022112095003442.

[29] Lian G, Thornton C, Adams MJ. A theoretical study of the liquid bridge forces between two rigid spherical bodies. J Colloid Interface Sci. 1993;161:138-147. DOI: 10.1006/jcis.1993.1452.

[30] Gac JM, Jackiewicz A, Werner Ł, Jakubiak S. Consecutive filtration of solid particles and droplets in fibrous filters. Sep Purif Technol. 2016;170:234-240. DOI: 10.1016/j.seppur.2016.06.057.

[31] Podgórski A, Maisser A, Szymanski WW, Jackiewicz A, Gradoń L. Penetration of monodisperse, singly charged nanoparticles through polydisperse fibrous filters. Aerosol Sci Tech. 2011;45(2):196-214. DOI: $10.1080 / 02786826.2010 .531300$. 
[32] Jackiewicz A, Podgórski A, Gradoń L, Michalski J. Nanostructured media to improve the performance of fibrous filters. KONA Powder Part J. 2013;30:244-255. DOI: 10.14356/kona.2013023.

[33] Jackiewicz A, Bałazy A, Podgórski A. Investigation of aerosol dispersion in fibrous filters. Pol J Chem Technol. 2008;10(1):66-72. DOI: 10.2478/v10026-008-0016-4.

[34] Bondar V, Freeman BD, Pinnau I, Gas transport properties of poly(ether-b-amide) segmental block copolymers. J Polym Sci B. 2000;38:2051-2062. DOI: 10.1002/1099-0488(20000801)38:15<2051::AID-POLB100>3.0.CO;2-D. 